\title{
Prinsip Kesantunan Berbahasa Karyawan dan Tamu di Homeschooling Primgama Palembang (Kajian Pragmatik)
}

\author{
Ninda Resti Tania \\ Email: rninda772@yahoo.com
}

\begin{abstract}
Abstrak - Tujuan penelitian untuk mendeskripsikan kesantunan berbahasa dan untuk mengetahui kesantunan berbahasa yang paling dominan digunakan karyawan dan tamu di homeschooling Primagama Palembang. Metode yang digunakan yaitu metode simak. Sumber data adalah tuturan karyawan dan tamu di homeschooling Primagama Palembang. Instrumen penelitian adalah peneliti sendiri (humen istrumen). Teknik pengumpulan data yang digunakan dalam penelitian adalah teknik sadap dan teknik catat. Adapun hasil penelitian. Teknik analisis data menggunakan metode padan pragmatik. Berdasarkan hasil analisis prinsip kesantunan berbahasa karyawan dan tamu di homeschooling Primagama Palembang, diperoleh 49 data tuturan yang terdiri dari 32 tuturan karyawan dan 17 tuturan tamu yang meliputi: (1) maksim kearifan, (2) maksim kedermawanan, (3) maksim Penghargaan (4) maksim kerendahan hati/kesederhanaan, (5) maksim kewajiban meminta Maaf, (6) maksim kewajiban tanggapan atau permintaan maaf, (7) maksim pemufakatan, (8) maksim pendapat, (9) maksim kesimpatian, dan (10) maksim perasaan.
\end{abstract}

\section{Kata Kunci-Prinsip Kesantunan, Karyawan dan Tamu}

\begin{abstract}
The purpose of this research is to describe the politeness of language and to find out the politeness of language that is most dominant used by employees and guests at Primagama Palembang homeschooling. The method used is the listening method. The data source is the speech of employees and guests at Primagama Palembang homeschooling. The research instrument was the researcher himself (humen instrument). Data collection techniques used in the study were tapping and note taking techniques. The research results. Data analysis techniques used the pragmatic equivalent method. Based on the results of the analysis of the politeness principle of employees and guests in Primagama Palembang homeschooling, 49 speech data were obtained consisting of 32 employee speeches and 17 guest speeches which included: (1) wisdom maxim, (2) philanthropic maxim, (3) maxim of appreciation (4) ) maxim of humility / simplicity, (5) maxim of obligation to apologize, (6) maxim of obligation of response or apology, (7) maxim of agreement, (8) maxim of opinion, (9) maxim of sympathy, and (10) maxim of feeling
\end{abstract}

Kayword-Principles of Politeness, Employees and Guests.

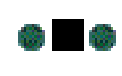

\section{PENDAHULUAN}

Bahasa ialah sebuah sistem lambang bunyi yang arbitrer yang digunakan oleh masyarakat untuk tujuan komunikasi. Bentuk yang paling nyata dalam komunikasi 
adalah bahasa. Fungsi bahasa sebagai alat komunikasi sangatlah penting. Bahasa sebagai alat komunikasi memiliki empat aspek keterampilan berbahasa, yaitu keterampilan menyimak, berbicara, membaca, dan menulis. Keempat keterampilan tersebut tidak dapat dipisahkan dalam komunikasi sehari-hari. Komunikasi ini ditunjukan untuk menumbuhkan hubungan sosial yang baik antar manusia sebagai makhluk yang tidak dapat hidup secara individu.

Djadjasudarma (2017:60), pragmatik adalah language in use, studi terhadap makna ujaran dalam situasi tertentu. Sifat-sifat bahasa dapat dimengerti melalui pragmatik, yakni bagaimana bahasa digunakan dalam komunikasi. Dalam bertutur selain memperhatikan kaidah atau aturan kebahasaan hendaknya juga meningkatkan keterampilan berbahasa secara santun, baik dalam ragam formal maupun nonformal. Bahasa dapat membentuk perilaku manusia. Jika kebiasaan berbahasa yang tertanam pada diri seseorang adalah kebiasaan berbahasa yang buruk, perilaku bahasanya pun juga akan tumbuh buruk. Oleh karena itu, jika ingin perilaku berbahasa seseorang tumbuh dan berkembang dengan santun, hendaknya ditanamkan pula kebiasaan berbahasa secara santun.

Menurut Chaer (2010:10-11), ada beberapa pakar yang membahas kesantunan berbahasa antara lain, Lakoff (1972), Fraser (1978), Brown dan Levinson (1978), dan Leech (1983). Para pakar itu membagi tiga kaidah agar tuturan terdengar santun. Secara singkat dan umum menurut para pakar itu ada tiga kaidah yang harus dipatuhi agar tuturan terdengar santun oleh pendengar atau lawan tutur. Ketiga kaidah itu diantaranya: (1) formalitas (formality), (2) ketidaktegasan (hesitancy), dan (3) kesamaan atau kesekawanan (equality or camaraderie). Dengan singkat bisa dikatakan sebuah tuturan disebut santun kalau ia tidak terdengar memaksa atau angkuh, tuturan itu memberi pilihan tindakan kepada lawan tutur, dan lawan tutur itu menjadi senang.

Kutipan di atas, merupakan faktor penting agar tuturan terdengar santun dan lawan tutur senang. Bertutur kata halus memiliki maksud yang dapat menyejukkan hati dan membuat orang lain berkenan. Jika setiap tuturan terdengar santun, hidup manusia akan penuh dengan kesejahteraan. Artinya pada saat seseorang berkomunikasi hendaknya dilakukan secara baik dan santun. Kaidah kesantunan dipakai dalam setiap tindak tutur baik dalam kegiatan formal maupun nonformal. Oleh karena itu, kesantunan berbahasa sangat penting bagi masyarakat dalam bertutur disetiap hal yang dilakukan dalam percakapan untuk menjalin hubungan yang baik antara penutur dan mitra tutur. Menjalin hubungan yang baik saat berkomunikasi bisa dilihat dari cara bicara baik atau tidak, bahasa yang digunakan santun atau tidak, karena tidak semua orang mengerti maksud tuturan yang kita ucapkan. Hal ini untuk mengurangi kesalahpahaman dan rasa tersinggung saat berkomunikasi antara penutur dan mitra tutur.

Kesantunan berbahasa dapat dilihat dari adanya pematuhan prinsip kesantunan berbahasa. Adapun prinsip kesantunan berbahasa menurut Leech (2014:91), terdiri dari dari sepuluh yaitu: (1) maksim kearifan (tact 
maxim), (2) maksim kedermawanan (generosity maxim), (3) maksim pujian (approbation maxim), (4) maksim kerendahan hati (modesty maxim), (5) maksim kewajiban meminta maaf (obligation apoligation thinking), (6) maksim kewajiban tanggapan atau permintaan maaf (obligation responses to thanks and apologies), (7) maksim kesepakatan (argement maxim), (8) maxim pendapat (opinion maxim), (9) maksim simpati (sympathy maxim), dan (10) maksim perasaan (feeling maxim). Jadi jika adanya pematuhan prinsip kesantunan berbahasa dalam tuturan maka tuturan tersebut dikatakan santun. Dalam penelitian ini peneliti akan meneliti prinsip kesantunan berbahasa karyawan dan tamu di homeschooling Primagama Palembang.

Menurut Seto Mulyadi (dalam Ahmad, 2015:9), homeschooling is an institution of education for improving students potencies in developing her/his creativity". Artinya Homeschooling adalah suatu lembaga pendidikan untuk meningkatkan potensi siswa dalam mengembangkan diri dan kreativitasnya. Homeschooling sebagai sistem pendidikan alternative yang saat ini menjadi pilihan orang tua untuk memberikan pendidikan kepada anak-anaknya. Dimana keberadaannya sah, diakui, sama dan sederajat dengan sekolah formal sesuai hukum Indonesia.

Homeschooling Primagama Palembang menjadi alternatif proses pendidikan yang memiliki standar ketercapaian materi yang kualitasnya sama dengan sekolah biasa, yaitu dengan menggunakan pendekatan akademik. Siswa diberikan pengajaran sesuai adengan tingkat kemampuan (sensitive learning), gaya belajar (style learning), dan karakter komunikasi. Kemudian akan terciptalah output anak didik yang memiliki bekal ilmu yang baik (knowledge), kecakapan hidup yang baik (lifeskill), dan juga sikap hidup yang baik (attitude). Agar itu semua dapat terwujud, karyawan Primagama Palembang diwajibkan memberikan pelayanan yang terbaik.

Penerapan kesantunan sangat penting dilakukan, salah satunya karyawan di homeschooling Primagama Palembang. Saat berkomunikasi semua karyawan dituntut untuk menerapkan kesantunan berbahasa, karena di lembaga pendidikan homeschooling Primagama Palembang melatih dan menanamkan kepada semua karyawan agar bertutur santun. Salah satu karyawan homeschooling Primagama Palembang yang harus menerapkan prinsip kesantunan dengan baik, yaitu staf administrasi akademik. Karyawan staf administrasi akademik sebagai karyawan membantu, melaksanakan dan melayani kegiatan yang ada di homeschooling karyawan staf administrasi akademik, sehingga karyawan staf administrasi akademik selalu berhadapan langsung dengan siswa, orang tua dan pengunjung lain yang ingin mendapatkan informasi seputar homeschooling dan lain-lain, oleh karena itu karyawan staf administrasi akademik dituntut menggunakan bahasa yang formal dan santun. Dari permasalahan di atas, kesantunan berbahasa sangat dibutuhkan karyawan homeschooling Primagama di Palembang.

Adapun alasan peneliti memilih homeschooling Primagama Palembang, karena homeschooling ini 
adalah salah satu sekolah mandiri berijazah kurikulum nasional dan internasional di kota Palembang. Adapun tingkatan belajar homeschooling dari SD, SMP bahkan SMA. Di homeschooling ini siswa dapat belajar di rumah bahkan di kantor homeschooling yang bertempatan di Jalan Teuku Umar No.8. 30 llir Barat.II. Kota Pelembang. Sumatera Selatan.

Terkait dengan latar belakang masalah di atas, penelitian terhadap kesantunan berbahasa perlu dilakukan mengingat pentingnya kesantunan berbahasa di lembaga pendidikan, khususnya homeschooling Primagama Palembang. oleh karena itu, penulis akan beranggapan bahwa penelitian mengenai prinsip kesantunan berbahasa karyawan dan tamu di homeschooling Primagama Palembang (kajian pragmatik) penting untuk diteliti.

Penelitian ini memfokuskan pada prinsip kesantunan berberbahasa karyawan dan tamu di homeschooling Primagama Palembang. Berdasarkan latar belakang yang telah dijabarkan sebelumnya, maka identifikasi masalah dalam penelitian ini adalah: (1) bagaimanakah prinsip kesantunan berbahasa karyawan dan tamu di homeschooling Primagama Palembang (kajian prgmatik) berdasarkan teori Leech?, (2) apa sajakah maksim kesantunan berbahasa yang dominan digunakan karyawan di homeschooling Primagama Palembang?, (3) apa sajakah maksim kesantunan berbahasa yang dominan digunakan tamu di homeschooling Primagama Palembang?, (4) Apa sajakah maksim kesantunan berbahasa yang dominan digunakan karyawan dan tamu di homeschooling Primagama Palembang?.

Agar permasalahan dalam penelitian ini tidak terlalu luas dan menyimpang dari sasaran yang diharapkan, maka peneliti membatasi penelitian pada prinsip kesantunan berbahasa karyawan dan tamu di homeschooling Primagama Palembang (kajian pragmatik) menurut Leech yang terdiri dari sepuluh maksim yang meliputi: (1) maksim kearifan (tact maxim), (2) maksim kedermawanan (generosity maxim), (3) maksim pujian (approbation maxim), (4) maksim kerendahan hati (modesty maxim), (5) maksim kewajiban meminta maaf (obligation apologizing thinking), (6) maksim kewajiban tanggapan atau permintaan maaf (obligation responses to thanks and apogies), (7) maksim kesepakatan (agreement maxim), (8) maksim pendapat (option maxim), (9) maksim simpati (sympathy maxim), dan (10) maksim perasaan (feeling maxim).

Berdasarkan latar belakang dan pembatasan masalah, maka rumusan masalah dalam penelitian ini, adalah: bagaimanakah prinsip kesantunan berbahasa karyawan dan tamu di homeschooling Primagama Palembang (kajian pragmatik) berdasarkan teori Leech?, apa sajakah maksim kesantunan berbahasa yang dominan digunakan karyawan dan tamu di homeschooling Primagama Palembang?

Adapun manfaat dari penelitian ini dapat digunakan bagi mahasiswa, dosen, peneliti lainnya dan lembaga homeschooling untuk memahami bidang pragmatik, khususnya kesantunan berbahasa, antara lain: (1) bagi mahasiswa, hasil penelitian ini diharapkan dapat menambah kajian dalam bidang pendidikan Bahasa dan Sastra Indonesia serta sebagai bahan bacaan atau 
reverensi bagi semua pihak, khususnya bagi mahasiswa

Pascasarjana Universitas PGRI Palembang, (2) bagi guru/dosen, hasil penelitian ini diharapkan dapat memberikan manfaat bagi pengembangan keilmuan sastra Indonesia terutama kesantunan berbahasa dan diharapkan sebagai payung untuk pedoman guru dalam pembelajaran bahasa Indonesia yang berkaitan dengan materi kesantunan berbahasa dan pragmatik, serta menambah wawasan baru pengembangan pengalaman pribadi dengan menerapkan prinsip kesantunan, (3) bagi peneliti lain, hasil penelitian ini diharapkan dapat menjadi informasi dan masukkan sekaligus acuan dalam melakukan penelitian sejenisnya, (4) bagi lembaga homeschooling, hasil penelitian diharapkan dapat menjadi evaluasi karyawan untuk melatih dan menanamkan kepada semua karyawan agar bertutur santun.

\section{METODE PENELITIAN}

Metode penelitian adalah cara yang digunakan oleh peneliti dalam pengumpulan data penelitiannya (Arikunto, 2013:203). Metode yang digunakan dalam penelitian ini yaitu metode simak. Metode simak dilakukan dengan memperhatikan penggunaan bahasa. Menurut Mahsun (2012:93), istilah menyimak tidak hanya berkaitan dengan penggunaan bahasa secara lisan, tetapi juga penggunaan bahasa secara tertulis. Dalam penelitian ini peneliti menyimak penggunaan secara lisan dan kemudian menganalisis kesantunan berbahasa program studi Magister Pendidikan Bahasa dan Sastra Indonesia

karyawan dan tamu di homeschooling Primagama Palembang.

Adapun langkah-langkah yang diterapkan peneliti dalam metode simak tersebut antara lain sebagai berikut.

1.Merekam percakapan penutur dan mitra tutur.

2.Mengumpulkan dan mencatat tuturan yang sudah direkam pada kartu data penelitian.

3.Mengidentifikasi data yang telah didengar dan dicatat berdasarkan prinsip kesantunan yang sesuai dengan masalah penelitian.

4.Menganalisis dan mendeskripsikan data penelitian.

\section{HASIL PENELITIAN DAN PEMBAHASAN}

Berdasarkan hasil penelitian, terdapat sepuluh maksim kesantunan berbahasa karyawan dan tamu di homeschooling Primagama Palembang. Adapun sepuluh maksim dalam prinsip kesantunan berbahasa tersebut yaitu: (1) maksim kearifan (tact maxim), (2) maksim kedermawanan (generosity maxim), (3) maksim pujian (approbation maxim), (4) maksim kerendahan hati (modesty maxim), (5) maksim kewajiban meminta maaf (obligation opologizing thanking), (6) maksim kewajiban tanggapan meminta maaf (obligation responses to thanks and apologies), (7) maksim kesepakatan (agreement maxim), (8) maksim pendapat (option maxim), (9) maksim simpati (sympathy maxim), dan (10) maksim perasaan (feeling maxim).

Berikut ini, paparan dari tuturan karyawan dan tamu di homeschooling Primagama Palembang yang mengandung prinsip kesantunan berbahasa. 
Tabel 1

Hasil Analisis Data Tuturan Karyawan dan Tamu

\begin{tabular}{|c|c|c|c|c|c|c|c|}
\hline \multirow{2}{*}{ No. } & \multirow{2}{*}{ Prinsip Kesantunan } & \multicolumn{2}{|c|}{ Jumlah Tuturan } & \multicolumn{2}{|c|}{ Persentase Tuturan } & \multirow{2}{*}{$\begin{array}{c}\text { Jumlah Tuturan } \\
\text { Karyawan dan } \\
\text { Tamu }\end{array}$} & \multirow{2}{*}{$\begin{array}{l}\text { Persenta } \\
\text { Tuturan }\end{array}$} \\
\hline & & Karyawan & Tamu & Karyawan & Tamu & & \\
\hline 1. & Maksim Kearifan & 8 & 1 & $25 \%$ & $5,88 \%$ & 9 Tuturan & $18,36 \%$ \\
\hline 2. & $\begin{array}{l}\text { Maksim } \\
\text { kedermawanan }\end{array}$ & 9 & 1 & $28,12 \%$ & $5,88 \%$ & 10 Tuturan & $20,40 \%$ \\
\hline 3. & Maksim Pujian & 1 & 1 & $3,12 \%$ & $5,88 \%$ & 2 Tuturan & $4,08 \%$ \\
\hline 4. & $\begin{array}{l}\text { Maksim Kerendahan } \\
\text { Hati }\end{array}$ & 1 & 1 & $3,12 \%$ & $5,88 \%$ & 2 Tuturan & $4,08 \%$ \\
\hline 5. & $\begin{array}{l}\text { Maksim Kewajiban } \\
\text { Meminta Maaf }\end{array}$ & 2 & 5 & $6,25 \%$ & $29,41 \%$ & 7 Tuturan & $14,28 \%$ \\
\hline 6. & $\begin{array}{l}\text { Maksim Kewajiban } \\
\text { Tanggapan atau } \\
\text { Permintaan Maaf }\end{array}$ & 1 & 2 & $3,21 \%$ & $11,76 \%$ & 3 Tuturan & $6,12 \%$ \\
\hline 7. & Maksim Kesepakatan & 1 & 2 & $3,21 \%$ & $11,76 \%$ & 3 Tuturan & $6,12 \%$ \\
\hline 8. & Maksim Pendapat & 6 & 1 & $18,75 \%$ & $5,88 \%$ & 7 Tuturan & $14,28 \%$ \\
\hline 9. & Maksim Simpati & 1 & 1 & $3,12 \%$ & $5,88 \%$ & 2 Tuturan & $4,08 \%$ \\
\hline
\end{tabular}




\begin{tabular}{|c|c|c|c|c|c|c|c|}
\hline & & & & & & \\
\hline 10. & Maksim Perasaan & 2 & 2 & $6,25 \%$ & $11,76 \%$ & 4 Tuturan & $8,16 \%$ \\
\hline & Jumlah Tuturan & $\begin{array}{c}32 \\
\text { Tuturan }\end{array}$ & $\begin{array}{c}17 \\
\text { Tuturan }\end{array}$ & $100 \%$ & $100 \%$ & $\begin{array}{c}49 \\
\text { Tuturan }\end{array}$ & $100 \%$ \\
\hline \multicolumn{7}{|c|}{ di Homeschooling Primagama Palembang }
\end{tabular}


Berdasarkan tabel di atas, dalam penggunaan maksim-maksim prinsip kesantunan yang digunakan karyawan dan tamu relatif sama, walaupun terdapat beberapa penggunaan maksim yang dominan digunakan karyawan dan tamu di homeschooling Primagama Palembang pada saat berkomunikasi. Hal ini dilatarbelakangi dalam komunikasi antara karyawan dan tamu di homeschooling Primagama Palembang tergolong dalam situasi formal yang membuat komunikasi menjadi santun. Oleh Karena itu,

salah satu penggunan maksim paling dominan yang digunakan karyawan dan tamu di homeschooling Primagama Palembang saat berkomunikasi yaitu maksim kedermawanan berjumlah 10 (Sepuluh) Tuturan. Adapun penjelasan dari maksim Kedermawanan atau kemurahan hati berprinsip bahwa kurangi keuntungan diri sendiri dan tambahi pengorbanan diri sendiri. Maksudnya penghormatan pada orang lain akan terjadi apabila orang dapat mengurangi keuntungan bagi dirinya sendiri dan memaksimalkan keuntungan pihak lain.

Agar lebih jelas, berikut ini adalah paparan dari analisis data tuturan karyawan dan tamu di homeschooling Primagama Palembang.

\section{Maksim Kearifan (Tact Maxim)}

Berdasarkan analisis data tuturan karyawan dan tamu di homeschooling Primagama Palembang, terdapat 49 data tuturan yang terdiri dari 29 tuturan karyawan dan 17 tuturan tamu di homeschooling Primagama Palembang.

Dari tuturan karyawan di homeschooling Primagama Palembang yang mengandung maksim kearifan (tact maxim), yaitu sebanyak 8 tuturan (25\%). Sedangkan, dari 17 tuturan tamu di homeschooling Primagama Palembang yang mengandung maksim kearifan (tact maxim), yaitu sebanyak 1 tuturan (5,88\%).

Jadi, penerapan maksim kearifan (tact maxim) di homeschooling Primagama Palembang tersebut telah sesuai dengan teori prinsip kesantunan Leech (2014:93), yang berprinsip bahwa kurangi kerugian orang lain dan tambahi keuntungan orang lain. Maksudnya, setiap penuturan harus berpegang teguh dengan prinsip untuk mengurangi keuntungan diri sendiri dan memaksimalkan keuntungan orang lain.

2.Maksim Kedermawanan (Generosity Maxim) Berdasarkan analisis data tuturan karyawan dan tamu di homeschooling Primagama Palembang, terdapat 49 data 
tuturan yang terdiri dari 29 tuturan karyawan dan 17 tuturan tamu di homeschooling Primagama Palembang.

Dari tuturan karyawan di homeschooling Primagama Palembang yang mengandung maksim kedermawanan (generosity maxim), yaitu sebanyak 9 tuturan (28,12\%). Sedangkan, dari 17 tuturan tamu di homeschooling Primagama Palembang yang mengandung maksim kedermawanan (generosity maxim), yaitu sebanyak 1 tuturan $(5,88 \%)$. Jadi, penerapan maksim kedermawanan (generosity maxim) di homeschooling Primagama Palembang tersebut telah sesuai dengan teori prinsip kesantunan Leech (2014:93), yang berprinsip bahwa kurangi keuntungan diri sendiri dan tambahi pengorbanan diri sendiri. Maksudnya, penghormatan pada orang lain akan terjadi apabila orang dapat mengurangi keuntungan bagi dirinya sendiri dan memaksimalkan keuntungan pihak lain.

\section{Maksim Pujian (Approbation Maxim)}

Berdasarkan analisis data tuturan karyawan dan tamu di homeschooling Primagama Palembang, terdapat 49 data tuturan yang terdiri dari 29 tuturan karyawan dan 17 tuturan tamu di homeschooling Primagama Palembang.

Dari tuturan karyawan di homeschooling Primagama Palembang yang mengandung maksim pujian (approbation maxim), yaitu sebanyak 1 tuturan $(3,12 \%)$. Sedangkan, dari 17 tuturan tamu di homeschooling Primagama Palembang yang mengandung maksim pujian (approbation maxim), yaitu sebanyak 1 tuturan $(5,88 \%)$. Jadi, penerapan maksim pujian (approbation maxim)di homeschooling Primagama Palembang tersebut telah sesuai dengan teori prinsip kesantunan Leech (2014:93), yang berprinsip bahwa kurangi kurangi cacian pada orang lain dan tambahi pujian pada orang lain. Maksudnya, maksim ini mewajibkan setiap penutur dapat memaksimalkan kerugian bagi diri sendiri, dan meminimalkan keuntungan diri sendiri.

4.Maksim Kerendahan Hati (Modesty Maxim)

Berdasarkan analisis data tuturan karyawan dan tamu di homeschooling Primagama Palembang, terdapat 49 data tuturan yang terdiri dari 29 tuturan karyawan dan 17 tuturan tamu di homeschooling Primagama Palembang.

Dari tuturan karyawan di homeschooling Primagama Palembang yang mengandung maksim kerendahan hati (modesty maxim), yaitu sebanyak 1 tuturan (3,12\%). Sedangkan, dari 17 tuturan tamu di homeschooling Primagama Palembang yang mengandung kerendahan hati (modesty maxim), yaitu sebanyak 1 tuturan (5,88\%). 
Jadi, penerapan kerendahan hati (modesty maxim) di homeschooling Primagama Palembang tersebut telah sesuai dengan teori prinsip kesantunan Leech (2014:93), yang berprinsip bahwa kurangi pujian pada diri sendiri dan tambahi cacian pada diri sendiri. Maksudnya, peserta tutur diharapkan dapat bersikap rendah hati dengan cara mengurangi pujian terhadap diri sendiri.

\section{Maksim Kewajiban Meminta Maaf (Obligation Opologizing Thanking) Berdasarkan analisis data tuturan} karyawan dan tamu di homeschooling Primagama Palembang, terdapat 49 data tuturan yang terdiri dari 29 tuturan karyawan dan 17 tuturan tamu di homeschooling Primagama Palembang.

Dari tuturan karyawan di homeschooling Primagama Palembang yang mengandung maksim kewajiban meminta maaf (obligation opologizing thanking), yaitu sebanyak 2 tuturan (6,25\%). Sedangkan, dari 17 tuturan tamu di homeschooling Primagama Palembang yang mengandung maksim kewajiban meminta maaf (obligation opologizing thanking), yaitu sebanyak 5 tuturan $(29,41 \%)$.

Jadi, penerapan maksim kewajiban meminta maaf (obligation opologizing thanking) di homeschooling Primagama Palembang tersebut telah sesuai dengan teori prinsip kesantunan Leech (2014:93), yang berprinsip bahwa kurangi kewajiban meminta maaf diri sendiri serta tambahkan kewajiban meminta maaf pada orang lain. Maksudnya, setiap penutur dapat memaksimalkan permintaan maaf kepada mitra tutur.

6.Maksim Kewajiban Tanggapan
Meminta Maaf (Obligation Responses
to Thanks and Apologies)
Berdasarkan analisis data tuturan karyawan dan tamu di homeschooling Primagama Palembang, terdapat 49 data tuturan yang terdiri dari 29 tuturan karyawan dan 17 tuturan tamu di homeschooling Primagama Palembang.

Dari tuturan karyawan di homeschooling Primagama Palembang, yang mengandung maksim kewajiban tanggapan meminta maaf (obligation responses to thanks and apologies), yaitu sebanyak 1 tuturan $(3,12 \%)$. Sedangkan, dari 17 tuturan tamu di homeschooling Primagama Palembang yang mengandung maksim kewajiban tanggapan meminta maaf (obligation responses to thanks and apologies), yaitu sebanyak 2 tuturan $(11,76 \%)$.

Jadi, penerapan maksim kewajiban tanggapan meminta maaf (obligation responses to thanks and apologies) di homeschooling Primagama Palembang tersebut telah sesuai dengan teori prinsip kesantunan Leech (2014:93), yang berprinsip bahwa kurangi kewajiban atau permintaan 
maaf oleh orang lain dan tambahi tanggapan pada diri sendiri. Maksudnya, peserta tutur diharapkan bisa berbesar hati untuk memberikan tanggapan atau permintaan maaf pada mitra tutur dengan cara mengurangi kepentingan diri sendiri.

\section{Maksim Kesepakatan (Agreement} Maxim)

Berdasarkan analisis data tuturan karyawan dan tamu di homeschooling Primagama Palembang, terdapat 49 data tuturan yang terdiri dari 29 tuturan karyawan dan 17 tuturan tamu di homeschooling Primagama Palembang.

Dari tuturan karyawan di homeschooling Primagama Palembang, yang mengandung maksim kesepakatan (agreement maxim), yaitu sebanyak 1 tuturan (3,12\%). Sedangkan, dari 17 tuturan tamu di homeschooling Primagama Palembang yang mengandung maksim kesepakatan (agreement maxim), yaitu sebanyak 2 tuturan $(11,76 \%)$.

Jadi, penerapan maksim kesepakatan (agreement maxim) di homeschooling Primagama Palembang tersebut telah sesuai dengan teori prinsip kesantunan Leech (2014:93), yang berprinsip bahwa kurangi ketidaksesuaian antara diri sendiri dengan orang lain dan tingkatkan persesuaian antara diri sendiri dengan orang lain. Maksudnya, penutur hendaknya berpegang pada prinsip untuk selalu mengurangi keuntungan diri sendiri dan memaksimalkan keuntungan pihak lain dalam kegiatan bertutur.

\section{Maksim Pendapat (Option Maxim) Berdasarkan analisis data tuturan} karyawan dan tamu di homeschooling Primagama Palembang, terdapat 49 data tuturan yang terdiri dari 29 tuturan karyawan dan 17 tuturan tamu di homeschooling Primagama Palembang.

Dari tuturan karyawan di homeschooling Primagama Palembang, yang mengandung maksim pendapat (option maxim), yaitu sebanyak 6 tuturan (18,75\%). Sedangkan, dari 17 tuturan tamu di homeschooling Primagama Palembang yang mengandung maksim pendapat (option maxim), yaitu sebanyak 1 tuturan $(5,88 \%)$. Jadi, penerapan maksim pendapat (option maxim) di homeschooling Primagama Palembang tersebut telah sesuai dengan teori prinsip kesantunan Leech (2014:93), yang berprinsip bahwa kurangi pendapat atau penilaian pada diri sendiri dengan orang lain melalu kesepakatan. Maksudnya, penutur cenderung melemahkan pendapat diri sendiri dengan orang lain, penutur kesepakatan.

\section{Maksim Simpati (Sympathy Maxim)} Berdasarkan analisis data tuturan karyawan dan tamu di homeschooling Primagama Palembang, terdapat 49 data tuturan yang terdiri dari 29 tuturan karyawan 
dan 17 tuturan tamu di homeschooling Primagama Palembang.

Dari tuturan karyawan di homeschooling Primagama Palembang yang mengandung maksim simpati (sympathy maxim), yaitu sebanyak 1 tuturan (3,12\%). Sedangkan, dari 17 tuturan tamu di homeschooling Primagama Palembang, yang mengandung simpati (sympathy maxim), yaitu sebanyak 1 tuturan (3,12\%).

Jadi, penerapan maksim simpati (sympathy maxim) di homeschooling Primagama Palembang tersebut telah sesuai dengan teori prinsip kesantunan Leech (2014:93), yang berprinsip bahwa kurangi antisipasi antara diri sendiri dengan orang lain dan perbesar simpati antara diri sendiri dengan orang lain. Maksudnya, bila lawan tutur memperoleh keberuntungan atau kebahagiaan penutur wajib memberikan selamat. Namun, sebaliknya jika lawan tutur mendapat kesulitan penutur sepantasnya menyampaikan bela sungkawa atas kejadian yang menimpa lawan tutur tanda kesimpatian penutur.

10. Maksim Perasaan (Feeling Maxim)

Berdasarkan analisis data tuturan karyawan dan tamu di homeschooling Primagama Palembang, terdapat 49 data tuturan yang terdiri dari 29 tuturan karyawan dan 17 tuturan tamu di homeschooling Primagama Palembang.
Dari tuturan karyawan di homeschooling Primagama Palembang, yang mengandung maksim perasaan (feeling maxim), yaitu sebanyak 2 tuturan $(6,25 \%)$. Sedangkan, dari 17 tuturan tam di homeschooling Primagama Palembang yang mengandung maksim perasaan (feeling maxim), yaitu sebanyak 2 tuturan (11,76\%). Jadi, penerapan maksim perasaan (feeling maxim) di homeschooling Primagama Palembang tersebut telah sesuai dengan teori prinsip kesantunan Leech (2014:93), yang berprinsip bahwa kurangi perasaan tidak senang dan tidak suka pada mitra tutur dan tambahi perasaan senang pada mitra tutur. Maksudnya, penutur dapat mengungkapkan sebanyak-banyaknya rasa senang kepada mitra tutur dan jangan ada perasaan tidak senang pada mitra tutur.

Berdasarkan uraian di atas maka karyawan dan tamu di homeschooling Primagama Palembang sama-sama menggunakan 10 (sepuluh) prinsip kesantunan berbahasa pada saat berkomunikasi diantaranya: (1) maksim kearifan (tact maxim), (2) maksim kedermawanan (generosity maxim), (3) maksim pujian (approbation maxim), (4) maksim kerendahan hati (modesty maxim), (5) maksim kewajiban meminta maaf (obligation opologizing thanking), (6) maksim kewajiban tanggapan meminta maaf (obligation responses to thanks and apologies), 
(7) maksim kesepakatan (agreement maxim),

(8) maksim pendapat (option maxim), (9) maksim simpati (sympathy maxim), dan (10) maksim perasaan (feeling maxim). Walaupun jumlah dan persentasenya berbeda beda pada setiap maksimnya. Kemudian, dapat diketahui bahwa maksim yang dominan digunakan karyawan di homeschooling Primagama Palembang adalah maksim kedermawanan, yaitu terdapat sebanyak 9 (sembilan) tuturan atau $(28,03 \%)$. Sedangkan maksim yang dominan digunakan tamu di homeschooling Primagama Palembang adalah maksim kewajiban meminta maaf, yaitu terdapat sebanyak 5 (lima) tuturan atau $(29,41 \%)$, sehingga dapat diketahui bahwa maksim yang dominan yang digunakan karyawan dan tamu di homeschooling Primagama Palembang adalah maksim kedermawanan, yaitu terdapat sebanyak 10 (sepuluh) tuturan atau (31,25\%).

Pada saat penelitian, peneliti juga melihat umur (usia), status, budaya mempengaruhi kesantunan berbahasa pada saat proses komunikasi berlangsung di homeschooling Primagama Palembang. Menurut peneliti penerapan kesantunan sangat penting dan perlu digunakan oleh karyawan di homeschooling Primagama Palembang saat berkomunikasi dengan tamu yang datang ke homeschooling Primagama Palembang, bahkan tamupun sebaliknya menerapkan kesantunan berbahasa di homeschooling Primagama Palembag ataupun di tempat dan lembaga lainnya. Karyawan homeschooling Primagama Palembang hendaknya menerapkan prinsip kesantunan dengan baik, yaitu staf administrasi akademik. Staf administrasi akademik sebagai karyawan membantu, melaksanakan serta melayani kegiatan yang ada di homeschooling Primagama Palembang, yang selalu berhadapan langsung dengan siswa, orang tua dan pengunjung lain yang ingin mendapatkan informasi seputar homeschooling dan lain-lain. Karyawan juga dituntut menggunakan bahasa yang formal dan santun. Oleh karena itu, kesantunan berbahasa sangat dibutuhkan karyawan di homeschooling Primagama Palembang.

\section{SIMPULAN DAN SARAN}

Berdasarkan hasil analisis kesantunan berbahasa karyawan dan tamu di homeschooling Primagama Palembang, diperoleh 49 data tuturan yang terdiri dari 32 tuturan karyawan dan 17 tuturan tamu, yaitu diantaranya: (1) maksim kearifan (tact maxim), (2) maksim kedermawanan (generosity maxim), (3) maksim pujian (approbation maxim), (4) maksim kerendahan hati (modesty maxim), (5) maksim kewajiban meminta maaf (obligation opologizing thanking), (6) maksim 
kewajiban tanggapan meminta maaf berikut.

(obligation responses to thanks and apologies),

(7) maksim kesepakatan (agreement maxim),

(8) maksim pendapat (option maxim), (9)

maksim simpati (sympathy maxim), dan (10)

maksim perasaan (feeling maxim). Adapun

hasil dari penelitian di homeschooling

Primagama Palembang didapatkan data

tuturan sebanyak 49 data tuturan, diantaranya

terdapat sebanyak 32 (tiga puluh dua) data

tuturan karyawan dan 17 (tujuh belas) tuturan

tamu di homeschooling Primagama

Palembang. Berdasarkan penjelasan di atas,

dapat diketahui bahwa maksim paling dominan

yang digunakan karyawan di homeschooling

Primagama Palembang adalah maksim

kedermawanan terdapat sebanyak 9

(sembilan) tuturan atau $(28,12 \%)$. Sedangkan

maksim paling dominan yang digunakan tamu

di homeschooling Primagama Palembang

adalah maksim kewajiban meminta maaf terdapat sebanyak 5 (lima) tuturan atau

$(29,41 \%)$. Sehingga dapat diketahui bahwa maksim paling dominan yang digunakan karyawan dan tamu di homeschooling Primagama Palembang adalah maksim kedermawanan terdapat sebanyak 10 (sepuluh) tuturan atau $(31,25 \%)$. Berdasarkan hasil penelitian dan pembahasan yang berkaitan dengan prinsip kesantunan berbahasa, peneliti memberikan saran sebagai

1. Lembaga pendidikan yang bersifat formal dan nonformal, diharapkan dapat memperhatikan dan menerapkan kesantunan berbahasa pada saat komunikasi berlangsung.

2. Peneliti lain, diharapkan dapat melakukan penelitian yang sama dengan menggunakan prinsip kesantunan berbahasa. Maka dari itu, masih perlu dilakukan penelitian lanjutan mengenai prinsip kesantunan dengan objek yang berbeda dari sebelumnya.

3. Lembaga homeschooling, diharapkan dapat mengevaluasi karyawan untuk melatih dan menanamkan kepada semua karyawan agar bertutur dengan baik dan santun dalam berhadapan dengan tamu.

\section{DAFTAR PUSTAKA}

Ahmad, Bazzarudin. 2015. Implementasi Pembelajaran Homeschooling Kak Seto Solo. Tesis. Universitas Sebelas Maret. Tidak di Terbitkan.

Arikunto, Suharsimi. 2013. Prosedur Penelitian: Suatu Pendekatan Praktik. Jakarta: PT Rineka Cipta.

Bachri, Bachtiar S. 2010. Meyakinkan Validitas Data Melalui Triangulasi pada Penelitian Kualitatif. Universitas Negri Surabaya. Surabaya. 
Chaer, Abdul. 2010. Kesantunan Berbahasa. Jakarta: Rineka Cipta.

Chaer, Abdul dan Agustina Leonie. 2010. Sosiolinguistik: Perkenalan Awal. Edisi Revisi. Jakarta: Rineka Cipta.

Cummings, Louise. 2007. Pragmatik Sebuah Perspektif Multidisipliner. Yogyakarta: Pustaka Pelajar.

Djajasudarma, Fatimah. 2017. Wacana dan Pragmatik. Bandung: PT Repika Aditama.

Handayani. 2016. Kesantunan Berbahasa Lisan Guru SMK Negeri 4 Bandar Lampung dalam Pembelajaran Bahasa Indonesia dan Implikasinya dalam Pengembangan Pendidikan Karakter Siswa SMK Tahun Pelajaran 2015/2016. Tesis. Jurusan Magister Pendidikan Bahasa dan Sastra Indonesia Universitas Lampung. Tidak Diterbitkan.

Leech, Geoffrey. 2014. The Pragmatics of Politenesss. New York: Oxford University Press 2014.

Lubis, Hamid Hasan. 2015. Analisis Wacana Pragmatik. Edisi Revisi. Bandung: Angkasa.

Mahsun. 2012. Metode Penelitian Bahasa Tahap Strategi, Metode, dan Tekniknya Edisi Revisi. Jakarta: PT Raja Grafindo Persada.

Markhamah. 2014. Prosiding Seminar Nasional Ketidaksantunan Berbahasa dan Dampaknya dalam Pembentukan
Karakter. Jurnal. Magister Pengkajian Bahasa Sekolah Pascasarjana Universitas Muhammadiyah Surakarta bekerjasama dengan Balai Bahasa Provinsi Jawa Tengah. Tidak Diterbitkan.

Mulyadi, Seto. 2007. Homeschooling Keluarga Kak Seto. Bandung: Kaifa.

Mulyani, Henny Sri. 2014. Kecendrungan Isi Rubrik Surat Pembaca di Harian Umum Pikiran Rakyat. Universitas Padjajaran. Jurnal. Vol. 13. No. 01 2014.

Mulyati. 2015. Terampil Berbahasa Indonesia. Jakarta: Kencana.

Moleong, Lexy. 2017. Metodologi Penelitian Kualitatif. Bandung: PT Remaja Rosda Karya.

Rahardi, Kunjana. 2005. Pragmatik Kesantunan Imperatif Bahasa Indonesia. Jakarta Erlangga.

Rahardi, Kunjana. 2009. Sosiopragmatik. Jakarta: Erlangga.

Rahman, Anita. 2017. Kesantunan Berbahasa Indonesia Masyarakat dan Polisi Pada Pemeriksaan Lalulintas Kepolisian Polres Gowa. Tesis. Jurusan Magister Pendidikan Bahasa dan Sastra Indonesia Universitas Negeri Makasar. Tidak Diterbitkan.

Rua, Anjas Usmana. 2018. Prinsip Kesantunan Berbahasa Karyawan dan Konsumen Pada Lembaga Kursus dan Pelatihan Palcomtech 
Cabang Opi Jakabaring Palembang. Tesis. Jurusan Magister Pendidikan Bahasa dan Sastra Indonesia Universitas PGRI Palembang. Tidak Diterbitkan.

Rusminto, N.E. 2009. Analisis Wacana Indonesia. (Buku Ajar). Bandar Lampung: Universitas Lampung.

Sudaryat, Yayat. 2014. Makna dalam Wacana: Prinsip-Prinsip Semantik dan Pragmatik. Bandung: Yrama Widya.

Sugiyono. 2017. Metode Penelitian Kuantitatif, Kualitatif dan $R$ \& $D$. Bandung: Alfabeta.

Suryati, Eti. Analisis Kesantunan Berbahasa dalam Argumentasi Rubrik Pemikiran Pembaca Surat Kabar Kedaulatan Rakyat Edisi Januari 2013, Relevansinya sebagai Bahan Pembelajaran Menulis Argumentasi, dan Skenario Pembelajaran Pada siswa Kelas X SMA. Tesis. Universitas Muhammadiyah. Tidak Diterbitkan.

Tarigan, Hendry Guntur. 2009. Pengajaran Pragmatik. Bandung: Angkasa.
Tim Penyusun. 2017. Pedoman Penulisan Tesis. Palembang: Program Pascasarjana Univesitas Pgri Palembang.

Tina Mulyana, Ajeng. 2018. Isu-isu Kritis Kebijakan Bahasa dan Pengajaran Bahasa. Universitas Subang. Jurnal. 4. 13. No. 1 Februari 2018. Tidak Diterbitkan.

Usmaini. 2012. Pragmatik dalam Novel Bak Rambut Dibelah Tujuh Karya

Muhammad Makhlori. Tesis. Jurusan Magister Pendidikan Bahasa dan Sastra Indonesia Universitas PGRI Palembang. Tidak Diterbitkan.

Pranowo. 2012. Berbahasa Secara Santun. Yogyakarta: Pustaka Pelajar.

Putrayasa, Ida Bagus. 2014. Kalimat Efektif (Diksi, Struktur, dan Logika). Edisi Revisi. Bandung: PT Refika Aditama.

Wiryotinoyo, Mujiyono. 2006. Analisis Pragmatik dalam Penelitian Penggunaan Bahasa. Jurnal. Universitas Jambi. Tidak Diterbitkan.

Yule, George. 2014. Pragmatik . Yogyakarta: Pustaka Pelajar. 